Document downloaded from:

http://hdl.handle.net/10251/46648

This paper must be cited as:

Velázquez Martí, B.; Estornell Cremades, J.; López Cortés, I.; Marti Gavila, J. (2012). Calculation of biomass volume of citrus trees from an adapted dendrometry. Biosystems Engineering. 112(4):285-292. doi:10.1016/j.biosystemseng.2012.04.011.

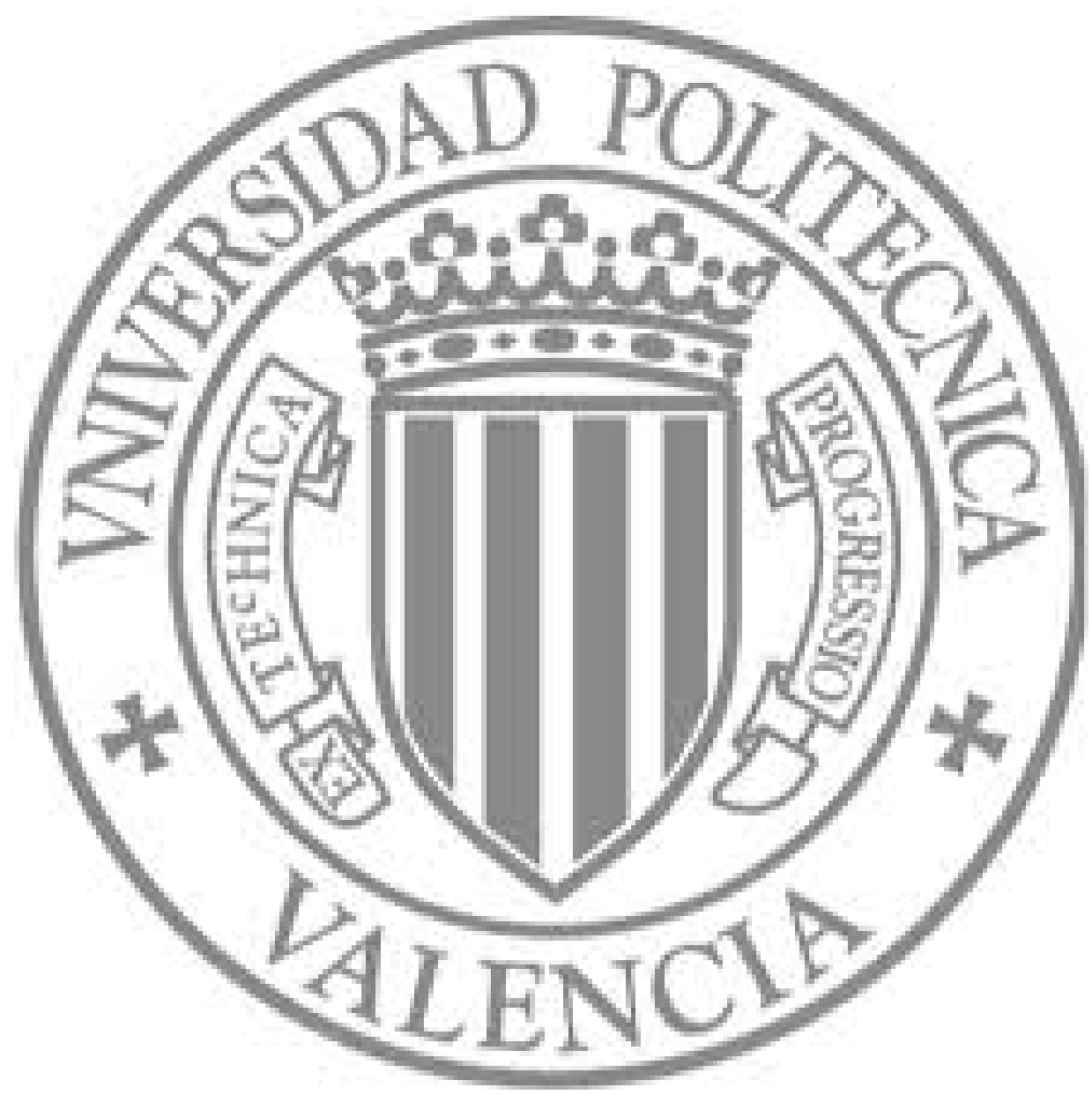

The final publication is available at

http://dx.doi.org/10.1016/j.biosystemseng.2012.04.011

Copyright Elsevier 


\section{Biosystems Engineering Manuscript Draft}

Manuscript Number: YBENG-D-11-00428

Title: Calculation of biomass volume of citrus trees from an adapted dendrometry

Article Type: Full Length Article

Keywords: bioenergy, energy wood, logistics, yield prediction, residues

Abstract: The aim of this work was to develop a suitable methodology and computational algorithms to calculate volumes and total biomass contained in citrus trees from an adapted dendrometry. This laid the foundations for the use of this methodology as a tool to manage resources from the orchards, establishing adequate predicting models for assessing other parameter such as incomes in raw materials for the cultivation, fruit production, $\mathrm{CO} 2$ sink, and waste materials (residual wood) used for energy or industry. The dendrometry has been traditionally applied to forest trees. However, little research has been conducted on fruit trees due to their structure is heterogeneous. To develop the process of biomass quantification it was necessary to perform systems of measurement, enabling to determine volumes of the analyzed trees. This issue was the first step of this research. Afterwards, relationships between actual volume (no hollows) and biomass of trees were established. To do this, form factors, real volume of crown (without holes), and occupation factor were calculated. Form factors relate actual volume of the branch or stem with the volume of a geometric model (solid of revolution). Occupation factors relate the crown model volume of a tree with the actual volume of solid material contained therein. These results could be correlated with production and quality of the fruit, with the amount of residual biomass coming from pruning, and with LiDAR data what may mean a simple, quick and accurate way to predict biomass. 
Highlights Paper: Calculation of biomass volume of citrus trees from an adapted dendrometry

1. It was developed a methodology for calculating the branch biomass of citrus from simple measurements.

2. Two approaches were followed for estimating the biomass contained in the crown, measuring its mean diameter and height.

3. The equations obtained allow calculating the volume of woody materials contained by the different structures of citrus.

4. The findings obtained could be used in production predictions (fruits and wastes) as well as their logistic.

5. This also allows estimating the $\mathrm{CO}_{2}$ captured by the trees from atmosphere in the photosyntesis. 


\title{
Calculation of biomass volume of citrus trees from an adapted dendrometry
}

\author{
B. Velazquez-Marti ${ }^{1}$, J. Estornell' ${ }^{2}$ I. López Cortés ${ }^{3}$, J. Martí-Gavilá2 \\ ${ }^{1}$ Departamento de Ingeniería Rural y Agroalimentaria, Universidad Politecnica de Valencia, Camino \\ de Vera s/n, 46022 Valencia (Spain) \\ ${ }^{2}$ Departamento de Ingeniería Cartográfica, Geodesia y Fotogrametría, Universidad Politecnica de \\ Valencia, Camino de Vera s/n, 46022 Valencia (Spain) \\ ${ }^{3}$ Departamento de Producción Vegetal, Universidad Politecnica de Valencia, Camino de Vera s/n, \\ 46022 Valencia (Spain)
}

e-mail of corresponding author: borvemar@dmta.upv.es

\section{Summary}

The aim of this work was to develop a suitable methodology and computational algorithms to calculate volumes and total biomass contained in citrus trees from an adapted dendrometry. This laid the foundations for the use of this methodology as a tool to manage resources from the orchards, establishing adequate predicting models for assessing other parameter such as incomes in raw materials for the cultivation, fruit production, $\mathrm{CO}_{2}$ sink, and waste materials (residual wood) used for energy or industry. The dendrometry has been traditionally applied to forest trees. However, little research has been conducted on fruit trees due to their structure is heterogeneous. To develop the process of biomass quantification it was necessary to perform systems of measurement, enabling to determine volumes of the analyzed trees. This issue was the first step of this research. Afterwards, relationships between actual volume (no hollows) and biomass of trees were established. To do this, form factors, real volume of crown (without holes), and occupation factor were calculated. Form factors relate actual volume of the branch or stem with the volume of a 
geometric model (solid of revolution). Occupation factors relate the crown model volume of a tree with the actual volume of solid material contained therein. These results could be correlated with production and quality of the fruit, with the amount of residual biomass coming from pruning, and with LiDAR data what may mean a simple, quick and accurate way to predict biomass.

Key word: bioenergy, energy wood, logistics, yield prediction, residues

\section{Introduction}

The dendrometry characterization of individual forest trees is an important issue to estimate volumes and to perform forest inventories. The difficulty in the direct determination of volume using section calculations make advisable to define allometric relations that, founded on unbiased samples and measured with accuracy, allow to estimate tree volume from simple measurements (Moscovich et al., 2004). This methodology is widely applied in forest trees, but not in fruit trees, what it makes necessary to adapt these algorithms to them.

To estimate biomass, direct and indirect methods can be selected. The first ones are destructive and involve cutting up trees and weighting each piece of wood (Parresol, 1999; Araujo et al., 1999). The second ones are found on the sum of wood volumes. Wood samples are clear cut and weighted to calculate the conversion factors what allow to obtain dry weight from volume (Arujo et al., 1999, Velazquez et al. 2010). Other procedures for estimating biomass are focused on the equations derived of regression analysis in which field measurement variables are considered such as the diameter at breast height $(\mathrm{DBH})$ and height $(\mathrm{H})$ (Araujo et al. 1999, Francis, 2000). This methodology is not destructive and it can be used for similar growths (Parresol 1999), being the approach to be used in this study. 
The development of new methodologies that allow to calculate variables associated to the crown with accuracy are relevant as these are related to the primary production (fruit and timber), and to the vigor of a tree (Schomaker et al., 1999). Some studies reported the importance of knowing crown characteristics for predictions of growths, waste materials (residual wood), fertilizer inputs, irrigation or pesticides (Doruska and Burkhart, 1994; Brunner, 1998). Furthermore, a large crown cover increases the protection and restoration of the soil and reduces the impact of rain and other erosive agents on it (Rodriguez et al., 2008). Knowledge of existing biomass and its relationship with these variables develops a new tool for planning the plantations, as well as the logistics of harvesting the fruit, or management of pruning. This is a tool for characterizing and cataloging tha plots and obtaining biomass surveys.

This research is focused on the development of a new methodology to predict actual volume and total biomass contained in citrus trees (mandarins and oranges) from an adapted dendrometry to be correlated with the production, residual biomass coming from pruning, or agronomics inputs for an efficient orchard management.

\section{Materials and Methods}

The aim of the measurement process was to determine the biomass contained in whole trees (stem and crown). The calculation of stem volume is simple, applying methods fully developed in forest science such as measurements of diameter and length along it. In contrast, the quantification of biomass contained in the crown is more complicated because the structure of crown in citrus trees is latifoliate and measurement methods fully developed do not exist. For this, a methodological proposal was performed in this work that consisted in the conception of the tree crown as a theoretical forest stand, in which each branch was considered as an individual (a tree). Attending on this concept the measurement process was carried out from the following steps : 
a. The volume measurement of the principal stem was performed, applying traditional dendrometric methods.

b. For estimating crown biomass, a number of branches in each stratum of formation was sampled (main branches, secondary branches, etc.). Then, the volumes of branches were measured being necessary to analyze the form parameters for each species according to the diametric class. To do this, an dendrometric analisys of the branch was done. Knowing the form parameters of the branches, dasometric methods were applied to estimate the total biomass in the crown.

2.1 Volume measurement of stem and branches

The dendrometric analysis of individuals (stem and branches) for measuring the volume and estimating the total biomass in the crowns was carried out in 50 plots, with variation of age, size of the trees, slope, orientation etc. The volume of each individual $V_{i}$ (branches or stem) was calculated from a global form coefficient $f$. This parameter was defined as the quotient between the real volume of a branch and a model geometric volume taken as reference for a branch or a stem (equation 1).

$$
f=\frac{\text { Real volume of the analized structure }}{\text { Volume of the model }}
$$

The model used for calculating the volume of a branch and stem was the cylinder. For the calculation of the real volume of a branch or stem, these were divided into at least five equal parts (Figure 1). The mean diameter of each section was obtainded as we measured an initial and end diameter for each interval. 
For actual volume calculation, each section was considered as a truncated cone, whose volume is calculated from equation 2. The sum of all section volumes was the real volume of the branch (Equation 3).

$$
\begin{gathered}
V_{i}=\frac{1}{3} \cdot \pi \cdot h \cdot\left(R^{2}+r^{2}+R \cdot r\right) \\
V_{\text {real }}=\sum_{1}^{i} V_{i}
\end{gathered}
$$

The global form factor should be a parameter characteristic of each species and diametric class for the geometric model tested. However, we analyzed the statistical variability of this parameter, calculating the average and the dispersion of all the classes. The determination of the form factor,allowed to consider the volume of the branches like a revolution solid (cylinder), calculating the real volume from simple measures, such us the diameter of the base and the length.

\subsection{Analysis of crown biomass}

All the branches of the stratum 1 (layer) were measured. This stratum corresponds to the branches of the crown base. The number of branches of this stratum is low ( $3-5$ branches), being their diameters the greatest. The following stratum was sampled, selecting several representative branches (short and long branches). The number of branches in the stratum was counted to determine the volume of existing biomass. Then, the number of bud or ramifications in successive strata was also counted, sampling again several branches of them. The total volume of each stratum was calculated separately, multiplying the mean value of the branch volume by the number of occurrences. Generally, the last stratum contains very small branches. For this reason, it was not possible its measurement considering the field method previously described. In this case, an 
external central branch and another one from the top of the crown were extracted of each sampled tree, and their volume were determined by submerging them into water in laboratory Multiplying the obtained volume and the number of branches of this stratum, its total volume was calculated. In addition, some representative branches were stripped, obtaining the percentage of the leaf mass.

The real volume of the 70 whole trees was determined, analyzing its evolution according to the age of the tree, diameter and height of the crown. The tendency to the concentration of the biomass in one or more layers was analyzed.

The model volume of the crown was calculated measuring its diameter and the height from the crown base to the apex. The purpose was to relate the model volume (material and hollows) with the real volume of material contained in the crown (only material: wood, leaves and fruits). The diameter of the crown was measured as an average of two segments that intersect in the centre of the crown projection forming an angle of $90^{\circ}$. The diameter and the height of the crown can be used to calculate volumes of different geometric models (Figure 3) that were compared to the real volume, and through the density with the biomass.

The relationship between the apparent volume of the crown and the real volume of the branches was called Occupation Factor, OF (equation 6). Knowing the occupation factor, the crown height, and the occupied surface, the real volume and the biomass of all the branches of a tree was calculated. The total biomass contained in an apparent volume (dasometric) of a tree was also evaluated, defined by the occupied area and the height of the tree.

$$
F O=\frac{\text { Volumen real of the crown }}{\text { Apparent volumen thecrown }}
$$




\section{Results and Discussion}

\subsection{Branches volume measurement}

The sampled branches were classified into four diametric classes. The percentages of the branches for each class are shown in the Figure 4 . The interval with diameters between 1 and $4 \mathrm{~cm}$ had the highest number of branches for mandarins (43.6\%), being the average diameter $2.6 \mathrm{~cm}$. For oranges, the maximum percentage of branches was found for diameters between 4 and $7 \mathrm{~cm}$ (49.8\%), being the average diameter $4.9 \mathrm{~cm}$. It is interesting to note that more than $70 \%$ of the branches had diameters lower than $7.0 \mathrm{~cm}$ for both tree species. This finding is particularly significant for planning industrial processes to which this residual biomass can be submitted. Knowing the most common diameters, then it can be fixed the final products, establishing drying, storage, and transport processes.

The form factor $\mathrm{f}$, calculated for the branches of orange and mandarin trees, is shown in the Table 1 . It can be observed that the number of average branches is very different between the two species, 173.50 branches for mandarin trees and 242.49 branches for orange trees. The lower number of average branches for mandarins can be explained by the fact that these trees are smaller. On the other hand, the average form factor for mandarins was 0.90 and for oranges 0.88 , remaining relatively constant for each stratum. The form factor for both species was very close to 1 using a cylindrical model, what means that this figure is suitable to model these branches. However, it was observed at field that the larger branches showed an oval section. This shape changed into a circular section as the branch progressed in length. This finding was in line with other studies (Díaz-Vaz, 1991) that found the formation of variable cross-sections in branches of different trees, especially when the weight was high and there was a response in the base, affecting the growth. 
The dispersion of the form factor made necessary to study its variation considering the diameter of the branch base, $D_{0}$, and its length $L$. Thus, several prediction models were calculated from these parameters to obtain the most suitable form factor (Table 2). On the other hand, regression models for estimating volume were also calculated, being the values of determination coefficient 0.97 for mandarins and 0.95 for oranges.

\subsection{Analysis of crown biomass}

The average actual volume of mandarin biomass was $0.0356 \mathrm{~m}^{3}$ and for oranges was $0.0520 \mathrm{~m}^{3}$. As observed in the Figure 5, the highest percentage of mandarin biomass was concentrated in the stratum $4(35.9 \%)$, what could be explained by the fact that mandarins have a large number of peripheral branches (diameters $<1 \mathrm{~cm}$ ), as verified at field. In oranges, the stratum 2 contained more biomass (49.2\%). In this case, the stratum 4 showed the lowest percentage of biomass since the density of the branches was lower and the crown was more open.

The table 4 shows the models for calculating the actual volume of all canopy branches using the crown diameter $(\mathrm{CD})$ and the crown height $(\mathrm{Hc})$. The best equation obtained was a multivariate quadratic model. The determination coefficient for mandarins was 0.802 and for oranges, 0.808 .

The table 5 contains the regression equations that correlate the actual volume of the tree crown with the volume of geometric models (hemisphere - cylinder) calculated from the $\mathrm{CD}$ and the Hc. The determination coefficients varied from 0.61 to 0.77 . For these analysis the paraboloid and the cone were not used as these models were proportional to the cylinder.

From crown diameter, it was calculated the area occupied by an average tree, being $5.9 \mathrm{~m}^{2} /$ tree in mandarins and $7.9 \mathrm{~m}^{2} /$ tree in oranges, what means that oranges provide greater shade cover. On the 
other hand, the occupation factor (OF) allow to determine the actual volume of the biomass contained in the crown multiplying this factor by the model volume selected (hemisphere, paraboloid, cone, and cylinder). This volume is calculated from the crown diameter (CD) and height (Hc) measured at field. The average and the standard deviation of the OF are shown in the Table 6. The greatest OF $\left(7.108 \mathrm{dm}^{3} / \mathrm{m}^{3}\right)$ corresponded to the hemispherical model, what means that this model shows less empty space inside the crown compared to the solid material contained by the crown.

It was analyzed the relationship between the OF using an hemispherical and cylindrical model and the variables $H_{c}$ and $D_{c}$. The best results were obtained for mandarins using a cylinder with a determination coefficient of 0.796 . For oranges the highest determination coefficient was 0.727 using an hemispherical model. These results indicate that the OF can be estimated with accuracy from simple measurements of the branches such as crown diameter and height.

\subsection{Stem volume}

For estimating the total biomass of each tree, the stem volume was calculated using Huber's formula. For trees without stem, it was determined a theoretical diameter by means of linear regressions, considering as dependent variable, the stem diameter, and as independent variable, the mean diameter of the branches belonging to the stratum,1. The average and the standard deviation of the stem volume for each species are shown in the Table 8.

The stem volume for both species showed a high deviation standard. For estimating tree volumes, the relationship between the amount of photosynthetic and non-photosynthetic tissues can be used (Waring, 1983). Thus, previous research estimated the stem volume from the crown calculation 
(Vanclay, 1994). In this study, it was used the inverse process, obtaining the crown volume from stem volume previously calculated.

The results of the regressions for estimating the crown actual volume are shown in Table 9. Good results were obtained for both species, $\mathrm{R}^{2}=0.811$ in mandarins and $\mathrm{R}^{2}=0.759$ in oranges, what indicates the high ability of the stem volume to predict the actual crown volume. However, some restrictions can be found as the stem volume shows high variability and not all citrus trees have stem, even though the species are the same or they are in the same environmental and culture characteristics (climate, soil, physiographic factors, watering, planting frame, type of pruning). In these situations the predictor variable cannot be measured and therefore, this model could not be used.

\subsection{Distribution of tree biomass}

The Table 10 contains the mean percentage of biomass for each crown stratum and stem. The stratum 5 corresponds to the peripheral branches, which were not possible to analyze by dendrometry, because of the small size of the diameters and the small length of the branches. Their volume was measured submerging them into water.

As can be observed in the Table 10, the mandarin stems provide $8.5 \%$ of the total biomass for an average tree and the stratum 5 contained the lowest percentage of volume (14.1\%). The stratum 4 had the maximum percentage of volume $(27.8 \%)$. For oranges, the stem contained $10 \%$ of total biomass of an average tree and the stratum 5, 9\%. The highest percentage of biomass was concentrated in the stratum $2(39.9 \%)$. For mandarins and oranges the central stratum contained around $80 \%$ of the total biomass. Consequently, in mandarins the crown contained $91.5 \%$ of biomass of an average tree. For oranges the percentage was $90 \%$. 


\section{Conclusions}

In this study, it was developed a methodology for calculating the branch biomass of citrus from simple measurements such as the diameter at $5 \mathrm{~cm}$ from the base and its length. From these data, the actual volume was calculated multiplying the cylinder volume by a form factor, calculated in this work. In addition, two approaches were followed for estimating the biomass contained in the crown, measuring its mean diameter and height. In the first one, regression models were calculated. In the second one, the actual volume of a tree was calculated considering the volume of a solid of revolution and an occupation factor, also defined in this study. Finally, the average stem volumes in oranges and mandarins were determined. From these results the volume of the crown biomass were calculated. The equations obtained allow calculating the volume of woody materials contained by the different structures of citrus trees. Applying the density to this volume, the total biomass of a tree was obtained.

Analyzing the distribution of biomass it was verified that the stratum 2 for oranges and the stratum 4 for mandarins showed the highest percentage of biomass, being $49.2 \%$ for oranges and $35.9 \%$ for mandarins. The covered soil area by each tree species was determined, being $7.9 \mathrm{~m}^{2} /$ tree in oranges and $5.9 \mathrm{~m}^{2} /$ tree in mandarins.

The findings obtained in this study could be used in production predictions (fruits and wood) as well as their logistic. Also they can be related with growths, waste materials (residual wood), fertilizer inputs, irrigation or pesticides among other variables. This also allows estimating the $\mathrm{CO}_{2}$ captured by the trees from atmosphere in the photosyntesis. From biomass data, a planning tool for plantations could be performed allowing their management. On the other hand, the results obtained in this study are the first step of a new research line in which these data will be correlated with LiDAR, what may mean a simple, quick and accurate way to predict biomass. 


\section{References}

Araujo, M., N. Higuchi, and J. Carvalho, 1999. Comparison of formula for biomass content determination in a tropical rain forest site in the state of Par. Brazil. Forest Ecology and Management [117], 43-52.

Brunner, A. 1998. A light model for spatially explicit forest stands models. Forest Ecology and Management [147], 19-46.

Díaz-Vaz, J. 1991. Alamo. Lignum [5], 24.

Doruska, D. and H. Burkhart, 1994. Modeling the diameter and locational distribution of branches within the crows of loblolly pine trees in unthinned plantations. Canadian Journal of Forest Research [24], 2362-2376.

Francis, J. 2000. Estimating biomass and carbon content of saplings in Puerto Rican secondary forests. Caribbean Journal of Science [36], 346-350.

Parresol, B. 1999. Assessing tree and stand biomass: a review with examples and critical comparisons. Forest Science [45], 573-593.

Rodriguez, R., S. Valencia, J. Meza, M. Capó, and A. Reynoso, 2008. Crecimiento y características de la copa de procedencias de Pinus gregii Engelm. Fitotecnia [31], 19-26.

Vanclay, J. 1994. Modeling Forest Growth and Yield: Applications to Mixed Tropical Forest. CAB International, London, England. 312 p

Velázquez-Martí B., Fernandez-Gonzalez E., Estornell J., Ruiz L.A. 2010. Dendrometric and dasometric analysis of the bushy biomass in Mediterranean forests. Forest Ecology and Management 259: 875-882

Waring, R. 1983. Estimating forest growth and efficiency in relation to canopy leaf area. Advances in Ecological Research [13], 327-354. 


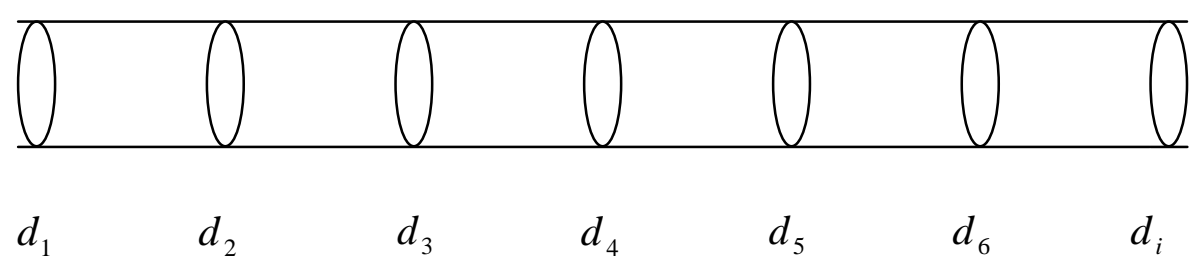

Figure 1. Measurements of diameters in each interval. 


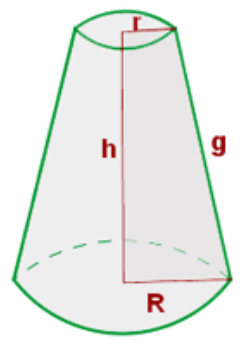

$$
\begin{gathered}
V_{i}=\frac{1}{3} \cdot \pi \cdot h \cdot\left(R^{2}+r^{2}+R \cdot r\right) \\
V_{\text {rea }}=\sum_{1}^{i} V_{i}
\end{gathered}
$$

Figure 2. Section of a truncated cone, where $R=$ maximum radius; $r=$ minimum radius; $h=$ length of the interval. 


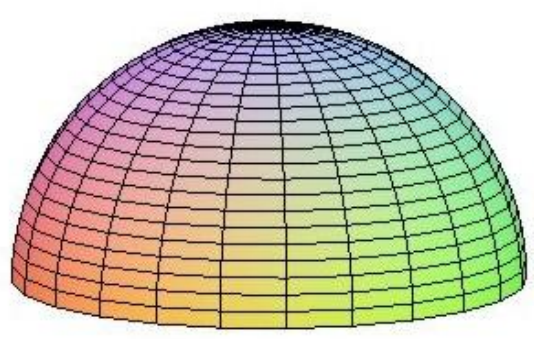

(a)

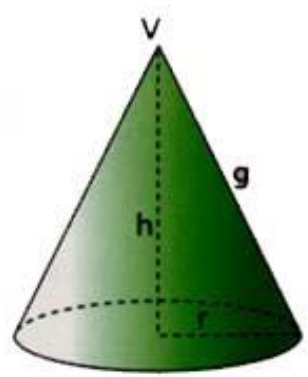

(c)

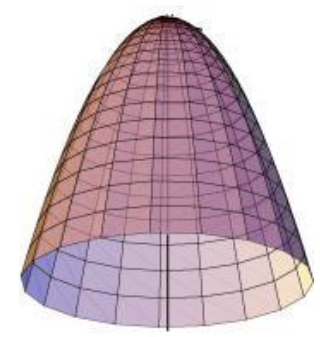

(b)

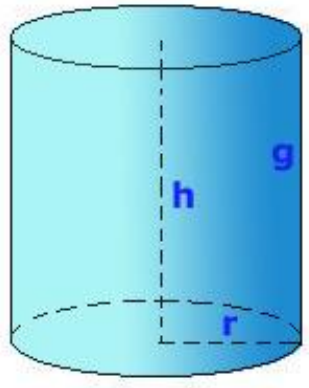

(d)

Figure 3. Growth models of tree crowns for each specie: (a) hemispherical, (b) paraboloidal, (c) conic, (d) cylindrical. 

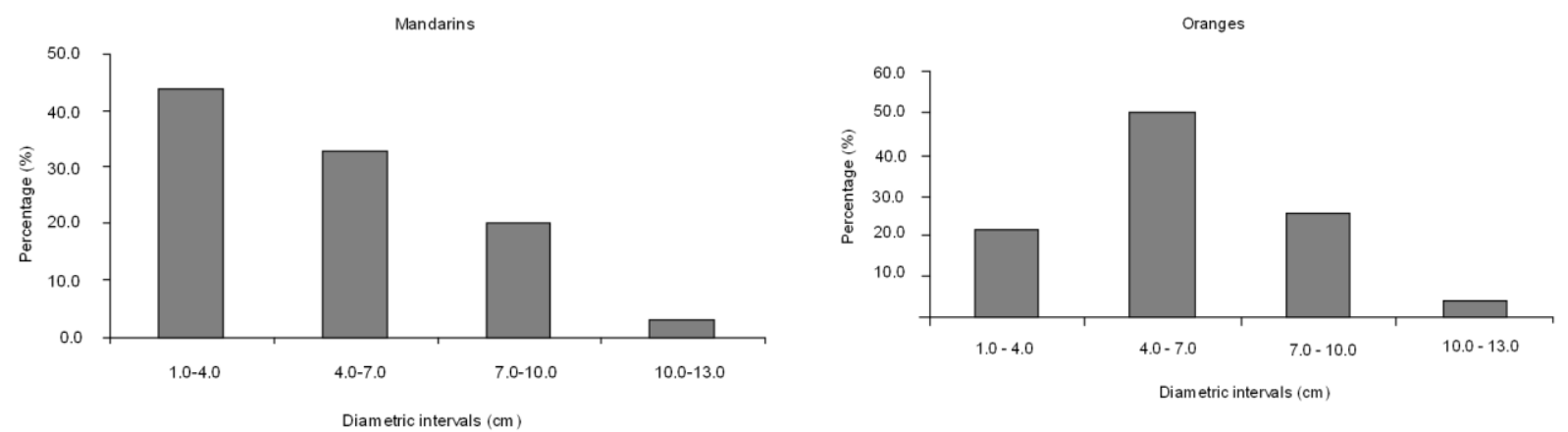

Figure 4. Distribution of the sampled branches of mandarins and oranges in percentages for each diametric interval. 


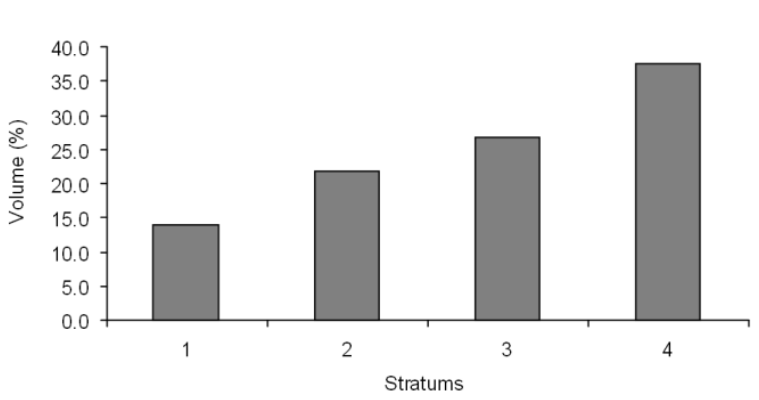

Mandarins

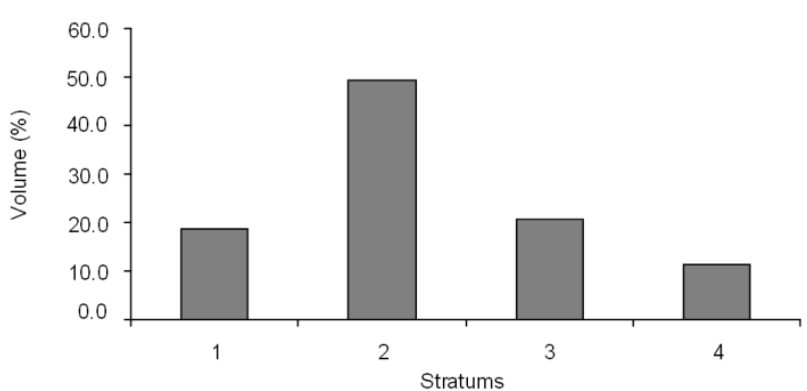

Oranges

Figure 5. Average volume in percentage for each stratum of mandarins and oranges. 


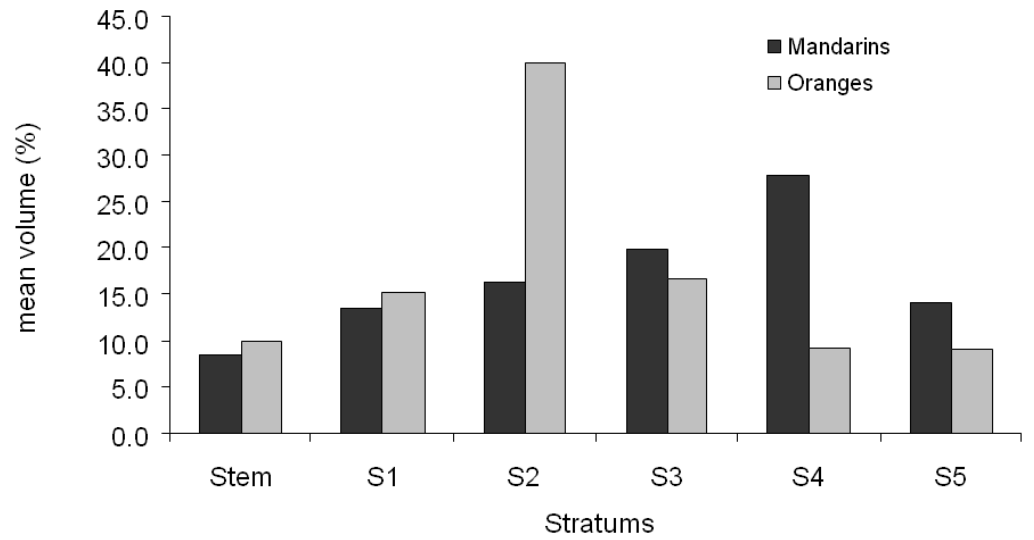

Figure 6. Biomass of an average tree for mandarins and oranges for each stratum and stem. 
Table 1. Number of branches, volume, and form factor for each stratum of mandarins and oranges.

\begin{tabular}{ccccccc}
\hline \multirow{2}{*}{ Species } & Variable & $\mathbf{N}$ & $\mathbf{v}\left(\mathbf{m}^{\mathbf{3}}\right)$ & $\boldsymbol{\sigma v}$ & $\square \mathbf{f}$ & $\boldsymbol{\sigma f}$ \\
\hline \multirow{3}{*}{ Mandarins } & E1 & 3.4 & 0.0062 & 0.0056 & 0.83 & 0.10 \\
& E2 & 8.21 & 0.0075 & 0.0069 & 0.89 & 0.12 \\
& E3 & 27.73 & 0.0092 & 0.0085 & 0.98 & 0.14 \\
& E4 & 133.22 & 0.0127 & 0.0091 & 0.91 & 0.21 \\
& TOTAL & $\mathbf{1 7 3 . 5}$ & $\mathbf{0 . 0 3 5 6}$ & $\mathbf{0 . 0 0 6 6}$ & $\mathbf{0 . 9}$ & $\mathbf{0 . 1 4}$ \\
\hline \multirow{3}{*}{ Oranges } & E1 & 3.39 & 0.0098 & 0.0066 & 0.89 & 0.04 \\
& E2 & 8.48 & 0.0256 & 0.0106 & 0.84 & 0.04 \\
& E3 & 41.93 & 0.0107 & 0.0062 & 0.86 & 0.06 \\
& E4 & 188.69 & 0.0059 & 0.0036 & 0.93 & 0.18 \\
& TOTAL & $\mathbf{2 4 2 . 4 9}$ & $\mathbf{0 . 0 5 2}$ & $\mathbf{0 . 0 4 0 4}$ & $\mathbf{0 . 8 8}$ & $\mathbf{0 . 0 1}$ \\
\hline
\end{tabular}

$N$ : Number of average branches, $v$ : Average volume $\left(\mathrm{cm}^{3}\right), \sigma v$ : standard deviation of volume, $\square f$ : average form factor, and $\sigma f$ : Standard deviation of $f$ 
Table 2. Equation of the form factor from the parameters $D_{0}(\mathrm{~cm})$ and $L(\mathrm{~cm})$.

\begin{tabular}{ccccc}
\hline Species & equation & $\mathbf{R}^{2}$ & $\boldsymbol{\sigma}_{\mathbf{X}}$ & MAE \\
\hline Mandarins & $f=1.27857-0.01978 \cdot L-0.03076 \cdot D_{0}+0.00023 \cdot D_{0}^{2}+0.00192 \cdot D_{0} L$ & 0.632 & 0.06 & 0.05 \\
& & & & \\
Oranges & $f=1.01779-0.00743 \cdot L+0.00105 \cdot L^{2}+0.00061 \cdot D_{0} L$ & 0.638 & 0.06 & 0.05 \\
\hline
\end{tabular}


Table 3. Models for estimating branch volume of citrus trees.

\begin{tabular}{llccc}
\hline \multicolumn{1}{c}{ Species } & \multicolumn{1}{c}{ Model $\left(\mathrm{cm}^{3}\right)$} & $\mathbf{R}^{2}$ & $\begin{array}{c}\boldsymbol{\sigma}_{\mathbf{X}} \\
(\mathbf{c m})\end{array}$ & $\begin{array}{c}\text { MAE } \\
(\mathbf{c m})\end{array}$ \\
\hline Mandarins & $\log V=-0.01112+0.9542 \cdot \log D_{0}^{2} L$ & 0.975 & 0.07 & 0.04 \\
Oranges & $\log V=0.08769+2.0286 \cdot \log D+0.277189 \cdot \log D_{0}^{2} L$ & 0.951 & 0.18 & 0.07
\end{tabular}

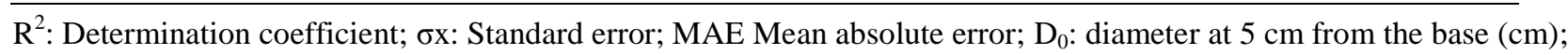

$L$ : Length of the branch in $\mathrm{cm}$. 
Table 4. Relationships between actual volume of the tree crown and CD and Hc in citrus trees.

\begin{tabular}{|c|c|c|c|c|}
\hline & Equation & $\mathbf{R}^{2}$ & $\sigma_{\mathbf{X}}\left(\mathbf{m}^{3}\right)$ & $\begin{array}{c}\text { MAE } \\
\left(\mathbf{m}^{3}\right)\end{array}$ \\
\hline Mandarins & $V=-0.25338+0.11103 \cdot C D-0.02238 \cdot C D \cdot H_{c}^{2}+0.05634 \cdot H_{c}^{2}$ & 0.802 & 0.004 & 0.003 \\
\hline Oranges & $V=0.08154-0.02276 \cdot C D^{2}-0.08489 \cdot C D+0.00164 \cdot C D \cdot H_{c}^{2}$ & 0.808 & 0.017 & 0.011 \\
\hline
\end{tabular}

$\mathrm{V}$ : tree crown volume $\left(\mathrm{m}^{3}\right), \mathrm{CD}$ : crown diameter $(\mathrm{m})$, and $\mathrm{H}_{\mathrm{c} \text { : }}$ tree crown height $(\mathrm{m})$. 
Table 5. Models for estimating volume of crown biomass from its diameter and height.

\begin{tabular}{|c|c|c|c|}
\hline Species & Model & Equation & $\mathbf{R}^{2}$ \\
\hline \multirow[b]{2}{*}{ Mandarins } & Hemisphere & $V=0.003 \cdot V_{s}^{1.498}$ & 0.672 \\
\hline & Cylinder & $V=0.0012 \cdot V_{c}^{1.15}$ & 0.612 \\
\hline \multirow[b]{2}{*}{ Oranges } & Hemisphere & $V=0.003 \cdot V_{s}^{1.5199}$ & 0.696 \\
\hline & Cylinder & $V=0.0016 \cdot V_{c}^{1.03}$ & 0.772 \\
\hline
\end{tabular}

$\mathrm{V}$ : tree crown volume $\left(\mathrm{m}^{3}\right) ; \mathrm{V}_{\mathrm{S}}$ : volume of a semispherical model $\left(\mathrm{m}^{3}\right) ; \mathrm{V}_{\mathrm{c}}$ v volume of a cylindrical model $\left(\mathrm{m}^{3}\right)$ 
Table 6. Occupation factors in citrus trees.

\begin{tabular}{lcccc}
\hline \multirow{1}{*}{ Model } & \multicolumn{2}{c}{ Oranges } & \multicolumn{2}{c}{ Mandarins } \\
& $\mathbf{O F}\left(\mathrm{dm}^{3} / \mathrm{m}^{3}\right)$ & $\boldsymbol{\sigma}_{\mathbf{~ O F ~}}\left(\mathrm{dm}^{3} / \mathrm{m}^{3}\right)$ & $\mathbf{O F}\left(\mathrm{dm}^{3} / \mathrm{m}^{3}\right)$ & $\boldsymbol{\sigma}_{\mathbf{O F}}\left(\mathrm{dm}^{3} / \mathrm{m}^{3}\right)$ \\
\hline Hemisphere & 8.673 & 6.658 & 7.108 & 4.467 \\
Paraboloid & 4.121 & 2.647 & 4.121 & 2.130 \\
Cone & 6.181 & 3.970 & 6.181 & 3.196 \\
Cilynder & 2.060 & 1.323 & 2.060 & 1.065 \\
\hline
\end{tabular}

OF: mean occupation factor $\left(\mathrm{dm}^{3} / \mathrm{m}^{3}\right) ; \sigma_{\mathrm{OF}}:$ standard deviation $\left(\mathrm{dm}^{3} / \mathrm{m}^{3}\right)$ 
Table 7. Relationships between the occupation factor and the diameter and height of the crown.

\begin{tabular}{|c|c|c|c|c|c|}
\hline & Model & Equation & $\mathbf{R}^{2}$ & $\sigma_{\mathbf{x}}$ & MAE \\
\hline \multirow[b]{2}{*}{ Mandarins } & Hemisphere & $\begin{array}{l}F O=-0.0294+0.00554 \cdot D_{c}^{2}-0.019478 \cdot D_{c} H_{c}-0.00848 \cdot D^{2} H+ \\
0.00286 \cdot D^{2} H^{2}-0.00978 \cdot D H^{2}+0.00761 \cdot H_{c}^{2}\end{array}$ & 0.720 & $1 \cdot 10^{-4}$ & $8 \cdot 10^{-5}$ \\
\hline & Cylinder & $\begin{array}{l}F O=0.42068-0.35232 \cdot D-0.40119 \cdot H+0.07392 \cdot D_{c}^{2}+0.33422 \cdot D_{c} H_{c}- \\
0.06975 \cdot D^{2} H+0.01625 \cdot D^{2} H^{2}-0.0783 \cdot D H^{2}+0.0946 \cdot H_{c}^{2}\end{array}$ & 0.796 & $8 \cdot 10^{-5}$ & $5 \cdot 10^{-5}$ \\
\hline \multirow[b]{2}{*}{ Oranges } & Hemisphere & $\begin{array}{l}F O=73.5674-22.1171 \cdot D_{c}^{2}+28.4339 \cdot D_{c} H_{c}-6.63543 \cdot D_{c} H_{c}^{2} \\
85.4819 \cdot H_{c}+19.6591 \cdot H_{c}^{2}\end{array}$ & 0.727 & 3.696 & 2.760 \\
\hline & Cylinder & $\begin{array}{l}F O=13.9659-3.6151 \cdot D_{c}+4.70896 \cdot D_{c} H_{c}-1.11893 \cdot D_{c} H \\
15.1879 \cdot H_{c}+3.48877 \cdot H_{c}^{2}\end{array}$ & 0.640 & 0.742 & 0.526 \\
\hline
\end{tabular}

OF: mean occupation factor $\left(\mathrm{dm}^{3} / \mathrm{m}^{3}\right) ; \mathrm{D}_{\mathrm{c}}$ : crown diamter $\left(\mathrm{m}^{3}\right) ; \mathrm{H}_{\mathrm{c}}$ : crown height $\left(\mathrm{m}^{3}\right)$ 
Tabla 8. Stem volume in mandarins and oranges.

\begin{tabular}{ccc}
\hline Species & Mean volume $\left(\mathbf{m}^{\mathbf{3}}\right)$ & $\boldsymbol{\sigma}_{\mathbf{X}}\left(\mathbf{m}^{\mathbf{3}}\right)$ \\
\hline Mandarins & 0.0043 & 0.0452 \\
Oranges & 0.0064 & 0.0692 \\
\hline \multicolumn{3}{c}{$\sigma_{\mathrm{v}}$ standard deviation }
\end{tabular}


Table 9. Regression models for estimating the crown actual volume from the stem volume.

\begin{tabular}{lcc}
\hline Species & Equation & $\mathbf{R}^{2}$ \\
\hline Mandarins & $V=0.0179+428.09 \cdot V_{f}^{2}+0.5805 \cdot V_{f}$ & 0.811 \\
Oranges & $V=0.0047-13.298 \cdot V_{f}^{2}+5.1103 \cdot V_{f}$ & 0.759 \\
\hline
\end{tabular}

V: crown actual volume $\left(\mathrm{m}^{3}\right) ; \mathrm{V}_{\mathrm{f}}$ : stem volume $\left(\mathrm{m}^{3}\right)$ 
Table 10. Total volume and biomass percentage of each stratum of an average tree.

\begin{tabular}{ccccccc}
\hline & \multicolumn{3}{c}{ Oranges } & \multicolumn{3}{c}{ Mandarins } \\
& $\mathbf{v}\left(\mathbf{m}^{\mathbf{3}}\right)$ & $\boldsymbol{\sigma}_{\mathbf{v}}$ & $\%$ & $\mathbf{v}\left(\mathbf{m}^{\mathbf{3}}\right)$ & $\boldsymbol{\sigma}_{\mathbf{v}}$ & $\%$ \\
\hline Stem & 0.0064 & 0.0069 & 10.0 & 0.0039 & 0.0045 & 8.5 \\
$\mathbf{S 1}$ & 0.0098 & 0.0466 & 15.3 & 0.0062 & 0.0058 & 13.5 \\
$\mathbf{S 2}$ & 0.0256 & 0.1286 & 39.9 & 0.0075 & 0.0073 & 16.2 \\
$\mathbf{S 3}$ & 0.0107 & 0.0062 & 16.7 & 0.0092 & 0.0087 & 19.9 \\
$\mathbf{S 4}$ & 0.0059 & 0.0136 & 9.2 & 0.0128 & 0.0067 & 27.8 \\
$\mathbf{S 5}$ & 0.0058 & - & 9.0 & 0.0065 & - & 14.1 \\
TOTAL & $\mathbf{0 . 0 6 4 2}$ & $\mathbf{0 . 2 0 1 9}$ & $\mathbf{1 0 0}$ & $\mathbf{0 . 0 4 6 0}$ & $\mathbf{0 . 0 3 3}$ & $\mathbf{1 0 0}$ \\
\hline
\end{tabular}

$\mathrm{v}$ average volume; $\sigma_{\mathrm{v}}$ standard deviation 